\title{
Subcellular Distribution of Cytokeratin and Vimentin in Malignant Rhabdoid Tumor: Three-Dimensional Imaging with Confocal Laser Scanning Microscopy and Double Immunofluorescence
}

\author{
Eijun Itakura, M.D., Sadafumi Tamiya M.D., Keisuke Morita, M.D., Hideki Shiratsuchi, M.D., \\ Yoshiaki Kinoshita, M.D., Yumi Oshiro, M.D., Yoshinao Oda, M.D., Shigeru Ohta, M.D., \\ Masutaka Furue, M.D., Masazumi Tsuneyoshi, M.D. \\ Department of Anatomic Pathology (EI, ST, HS, YK, YO, YO, MT) and Department of Dermatology (KM, \\ MF), Graduate School of Medical Sciences, Kyushu University, Fukuoka, Japan; and Department of \\ Pediatrics, Shiga University of Medical Science (SO), Otsu, Shiga, Japan
}

Malignant rhabdoid tumor (MRT) is a highly aggressive neoplasm that mostly occurs in childhood, characterized histologically by rhabdoid cells as shown by eosinophilic intracytoplasmic inclusions. Although it is known that rhabdoid cells co-express cytokeratin (CK) and vimentin, the distribution patterns of these two kinds of intermediate filaments and structural relationship between them are still not known.We investigated the subcellular distribution of CKs 8 and 18 and vimentin in MRT cell lines (Tm87-16, STM91-01, TTC549, and TC289) using confocal laser scanning microscopy and double immunofluorescence, in addition to ultrastructural examination. Vimentin was diffusely expressed in the cytoplasm of MRT cells, focally forming a filamentous network. In contrast, CKs 8 and 18 were partially expressed in the cytoplasm of MRT cells, forming globules or a few vague agglomerates. Three-dimensional images in TC289 cells revealed distinct distribution patterns of cytokeratin and vimentin, showing agglomerates of cytokeratins within the vimentin filament network.We conclude that these globules and agglomerates of CKs 8 and 18 correspond with the characteristic ultrastruc-

Copyright (C) 2001 by The United States and Canadian Academy of Pathology, Inc.

VOL. 14, NO. 9, P. 854, 2001 Printed in the U.S.A.

Date of acceptance: March 19, 2001.

Supported in part by a Grant-in-Aid for Cancer Research from the Fukuoka Cancer Society, Fukuoka and a Grant-in-Aid for General Scientific Research from the Ministry of Education, Science, Sports and Culture (Grants 09470052 and 12670167), Tokyo, Japan.

Address reprint requests to: Masazumi Tsuneyoshi, M.D., Department of Anatomic Pathology, Graduate School of Medical Sciences, Kyushu University, Maidashi 3-1-1, Higashi-ku, Fukuoka 812-8582, Japan; e-mail: masazumi@surgpath.med.kyushu-u.ac.jp; fax: +81-92-642-5968. tural finding, showing cytoplasmic bundles of intermediate filaments concentrated in whorled arrays.

KEY WORDS: Confocal laser scanning microscopy, Cytokeratin, Intermediate filament, Malignant rhabdoid tumor, Vimentin.

Mod Pathol 2001;14(9):854-861

Malignant rhabdoid tumor (MRT) was originally described in 1978 (1) as a renal malignant neoplasm of infancy and early childhood. This tumor is extremely rare and highly aggressive. Histologically, MRT is composed of monomorphous sheets of round or polygonal cells with intracytoplasmic eosinophilic inclusions, referred to as $r h$ abdoid cells $(1,2)$. Ultrastructural studies have revealed that the inclusions consist of compact bundles or whorls of intermediate filaments 6 to $10 \mathrm{~nm}$ in thickness $(2,3)$. Subsequently, extrarenal MRTs with morphologic features substantially similar to their renal counterparts have been reported, particularly in a variety of soft tissues (3-5) and in the central nervous system (6-8). Several immunohistochemical analyses have been conducted to support the characteristics of the MRT, most of which show immunoreactivity for both cytokeratin (CK) and vimentin intermediate filaments $(8-11)$. However, distribution patterns of the two kinds of intermediate filaments and structural relationship between them are still not known.

We conducted this study to clarify the subcellular distribution of CK and vimentin in MRT cells using electron microscopy, confocal laser scanning microscopy (CLSM), and double immunofluorescence. Three-dimensional (3-D) imaging was useful for revealing the structural relationships between CKs 8 and 18 and vimentin in MRT cells. 


\section{MATERIALS AND METHODS}

\section{Cell Culture}

Three MRT cell lines (Tm87-16, STM91-01, and TTC549) were donated from Shiga University of Medical Science (Shiga, Japan). Tm87-16 was established from malignant pleural effusion in a 21month-old boy with a retroperitoneal mass, which was in fact extrarenal MRT (12). STM91-01 was established from pulmonary metastasis in an 8-month-old boy with a left renal MRT (13). TTC549 was established from MRT of the liver in a 6 -month-old girl (14). Clinical data on the patients whose tumors were used to establish these cell lines are summarized in Table 1. Cytogenetic findings of original tumors are also shown in Table 1. The molecular characteristics of Tm87-16, STM91-01, and TTC549 have been described in detail elsewhere (15). We recently established the cell line TC289 derived from the malignant rhabdoid tumor of kidney of a 1-year-old boy at the primary site (16). These cell lines were cultured and maintained in RPMI-1640 supplemented with $10 \%$ fetal bovine serum in a humidified atmosphere of $5 \% \mathrm{CO}_{2}$ and $95 \%$ air at $37^{\circ} \mathrm{C}$.

\section{Electron Microscopic Study}

The cells were fixed in 3\% glutaraldehyde solution (buffered $\mathrm{pH}$ 7.4) and were postfixed in $1 \%$ phosphate buffered osmium tetroxidate. After hydration, the tissue blocks were embedded in Epon 812 resin (TAAB Laboratories, Berks, UK) and cut on an ultramicrotome (Ultracut E; Reichert-Jung, Vienna, Austria). Ultrathin sections were stained with uranyl acetate and lead citrate and examined under a JEM $100 \mathrm{C}$ electron microscope (Jeol, Tokyo, Japan).

\section{Fluorescent Labeling of Antibodies}

FluoReporter Protein Labeling Kits (Molecular Probes, Eugene, OR) were used for labeling monoclonal antibodies (MoAbs) fluorescently. To avoid photobleaching caused by long exposure times during the CSLM analysis, we performed this study with rhodamine Red-X (absorption and emission maxima at 570 and $590 \mathrm{~nm}$, respectively) and a new fluorescent dye, Oregon Green 488 (absorption and emission maxima at 496 and $524 \mathrm{~nm}$, respectively).
Compared with fluorescein isothiocyanate (FITC), Oregon Green 488 is highly photostable.

Commercial MoAbs against CK $8(20.4 \mathrm{mg} / \mathrm{mL}$; $35 \beta \mathrm{H} 11$; DAKO, Glostrup, Denmark), CK 18 (19.6 $\mathrm{mg} / \mathrm{mL}$; DC 10; DAKO), and vimentin $(14.3 \mathrm{mg} / \mathrm{mL}$; V9; DAKO) were purchased from the manufacturers. Each primary antibody (100 $\mu \mathrm{L}$ volume) was diluted 1:1 in phosphate buffered saline (PBS), $\mathrm{pH}$ 7.4 , with the addition of $20 \mu \mathrm{L}$ of $1 \mathrm{~m}$ bicarbonate. Anti-CK8 MoAb and anti-CK18 MoAb were respectively incubated for 1 hour in the dark at room temperature with Rhodamine Red-X solution $(0.72$ $\mathrm{mg} / \mathrm{mL}$ final). Anti-vimentin antibody was also incubated for 1 hour in the dark at room temperature with Oregon Green 488 solution $(0.17 \mathrm{mg} / \mathrm{mL}$ final). Reaction was stopped by the addition of hydroxylamine. This also allowed the dyes to be removed from unstable conjugates. After 30 minutes of incubation at room temperature, the fluorescent antibodies were separated from free fluorescent dyes by centrifugation at $1100 \times g$ for 5 minutes, using spin columns that contained 30,000-molecular weightsize exclusion resin in PBS with 2 mm sodium azide.

\section{Flow Cytometry}

Single-cell suspensions were prepared by treatment of the cultured cells with $0.25 \%$ trypsin and 1 mM EDTA in PBS. After being washed with PBS, $10^{5}$ cells were incubated with $5 \mu \mathrm{L}$ of Oregon Green 488-labeled anti-vimentin MoAb and Rhodamine Red-X-labeled anti-CK $18 \mathrm{MoAb}$ for 30 minutes at $4^{\circ} \mathrm{C}$. The cells were washed and fluorescenceanalyzed on an EPICS XL flow cytometer (Coulter, Hialeah, FL).

\section{Double-Labeling Immunofluorescence and Confocal Scanning Laser Microscopic Assessment}

Direct immunofluorescence was performed on all four MRT cell lines. MRT cells were cultured on a Lab-Tek chamber slide (Nalge Nunc International, Naperville, IL). Cell culture medium was removed, and cells were rinsed three times with PBS for 5 minutes each, fixed in $4 \%$ paraformaldehyde with $0.01 \mathrm{M}$ PBS for 30 minutes at $4^{\circ} \mathrm{C}$, and then rinsed three times with PBS for 5 minutes each. Some slides were stained by conventional hematoxylin and eosin for cytologic examination. For dou-

TABLE 1. Clinical Features and Detailed Karyotypes of the MRT Cell Lines

\begin{tabular}{lcclll}
\hline Cell Lines & Age $($ Mo $)$ & Sex & Primary Site & Outcome & \multicolumn{1}{c}{ Karyotypes } \\
\hline Tm87-16 & 21 & M & Retroperitoneum & Died (2 mo) & $46, X Y, t(11 ; 22)(\mathrm{p} 15.5 ; \mathrm{q} 11.23)$ \\
TTC549 & 6 & F & Liver & Died & $46, X X, \operatorname{del}(22)(\mathrm{q} 11.2)$ \\
STM91-01 & 8 & M & Kidney & Died (6 mo) & $46, X Y,-22, t(2 q ; 10 q), t(4 q ; 15 q), d e l(22)(q 11.2),+$ mar \\
TC289 & 12 & M & Kidney & Died (9 mo) & 47, add(X)(q22),Y,add(1)(p36),add(9)(p11),add(9)(q22),+19 \\
\hline
\end{tabular}


ble staining, pairs of Oregon Green 488-labeled antibody and Rhodamine Red-X-labeled antibody (anti-CK 8 and anti-vimentin; anti-CK 18 and antivimentin) were chosen. Cells were incubated overnight at $4^{\circ} \mathrm{C}$ in a mixture of V9 conjugated to Oregon Green 488 , plus either $35 \beta \mathrm{H} 11$ or DC 10 conjugated to Rhodamine Red-X. Slides were rinsed three times in PBS and mounted in a counterstaining and antifading medium, DAPI II Counterstain (Vysis Inc., Downers Grove, IL), which is a mixture containing 4', 6-diamidino-2-phenylindole and p-phenylenediamine in PBS and glycerol, between a slide and a coverslip sealed by nail varnish. Triplefluorescent slides were viewed with a $40 \times$ or $100 \times$ objective lens using conventional fluorescence microscopy, Axiophot (Zeiss, Thornwood, NY).

To extend our study of the subcellular distribution of vimentin and cytokeratin intermediate filaments networks in MRT cells, we performed confocal laser scanning microscopy. Confocal optical sections were collected with a confocal scanning laser microscope, model LSM-GB200 (Olympus, Tokyo, Japan), which was equipped with krypton and argon laser sources, by using a $100 \times$ objective lens (Plan-Apo, 1.4 NA, oil immersion). For the observation of double-stained preparations, simultaneous excitation was evoked at both $488 \mathrm{~nm}$ for Oregon Green 488 and $568 \mathrm{~nm}$ for Rhodamine Red-X with a scan speed of 40 seconds. No detectable cross-talk signal of the fluorescent dyes was recognized, which was carefully verified for all sections. For whole-mount preparations, final images were obtained by extended focus; optical sections at intervals of 0.3 to $0.6 \mu \mathrm{M}$ were projected on a single plane, extending for 6.5 to $19 \mu \mathrm{M}$ in thickness.

Neither Oregon Green 488 nor Rhodamine Red-X fluorescence presented any problems of bleaching during sessions, even in the case of long exposures ( $>25 \mathrm{~min}$ ). We processed the confocal $\mathrm{Z}$ series of 20 to 40 images for a three-dimensional image including stereoscopic imaging using NIH image 1.62 or Adobe Photoshop 4.0.1 (Adobe Systems, Inc., San Jose, CA) on a Power Macintosh G3 (Apple Computer Inc., Cupertino, CA).

\section{RESULTS}

\section{Ultrastructural Findings}

The cytoplasmic feature of the MRT cells was the presence of bundles of cytoplasmic filaments, concentrated in whorled arrays (Fig. 1). The filaments were approximately $10 \mathrm{~nm}$ in diameter and represented intermediate filaments. These filamentous inclusions varied in size and arrangement from cell to cell.

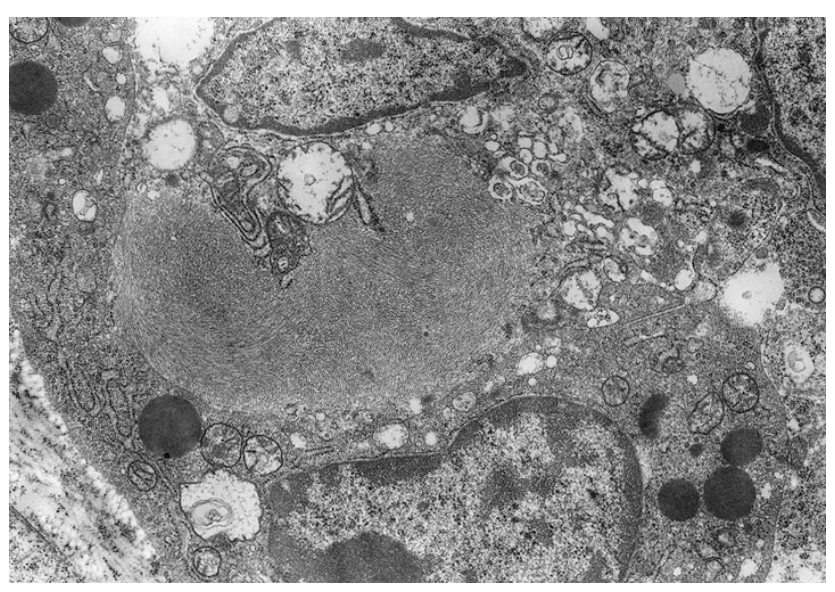

FIGURE 1. Ultrastructure showing a typical aggregation of whorls of intermediate filaments compressing a nucleus (Case TC289, 7500×).

\section{Flow Cytometry Analysis}

As revealed in Figure 2, 66.4 to $80.0 \%$ of MRT cells expressed vimentin, and 18.6 to $47.6 \%$ of MRT cells expressed CK 18. Not all vimentin-positive cells expressed CK 18 (18.6 to $47.6 \%$ did), but all CK 18 cells were vimentin positive. Patterns of co-expression of CK 18 and vimentin were the same in all MRT cells.

\section{Confocal Laser Scanning Microscopical Findings}

Although double immunofluorescence performed with antibodies against CKs 8 and 18 (Rhodamine Red-X) and vimentin (Oregon Green 488) using conventional fluorescence microscopy showed co-expression of the two kinds of intermediate filaments in some parts of cytoplasm of MRT cells, simultaneous confocal imaging with double immunofluorescence emission was very specific for detection of each of the fluorochromes used in overlap figures of Rhodamine Red-X and Oregon Green 488 spectra.

\section{Tm87-16}

Tm87-16 cells were composed of round cells, a few giant cells, and a few spindle-shaped cells (Fig. 3A). These cells showed distinct subcellular localization of vimentin and cytokeratins. Cytokeratins were mainly expressed as clusters of globules (Fig. 3B). In some cells, cytokeratins polarized as clumps along the cell periphery (Fig. 3C). Vimentin was strongly expressed at the rim of the cytoplasm. The vimentin pattern was a cordlike or incomplete filamentous pattern (Fig. 3B).

\section{TTC549}

TTC549 cells were mainly composed of round cells with a few giant cells (Fig. 4A). These cells showed relatively vague subcellular localization of vimentin and cytokeratins. Cytokeratins were diffusely expressed (Figs. 4B-C) focally in a dot pattern 

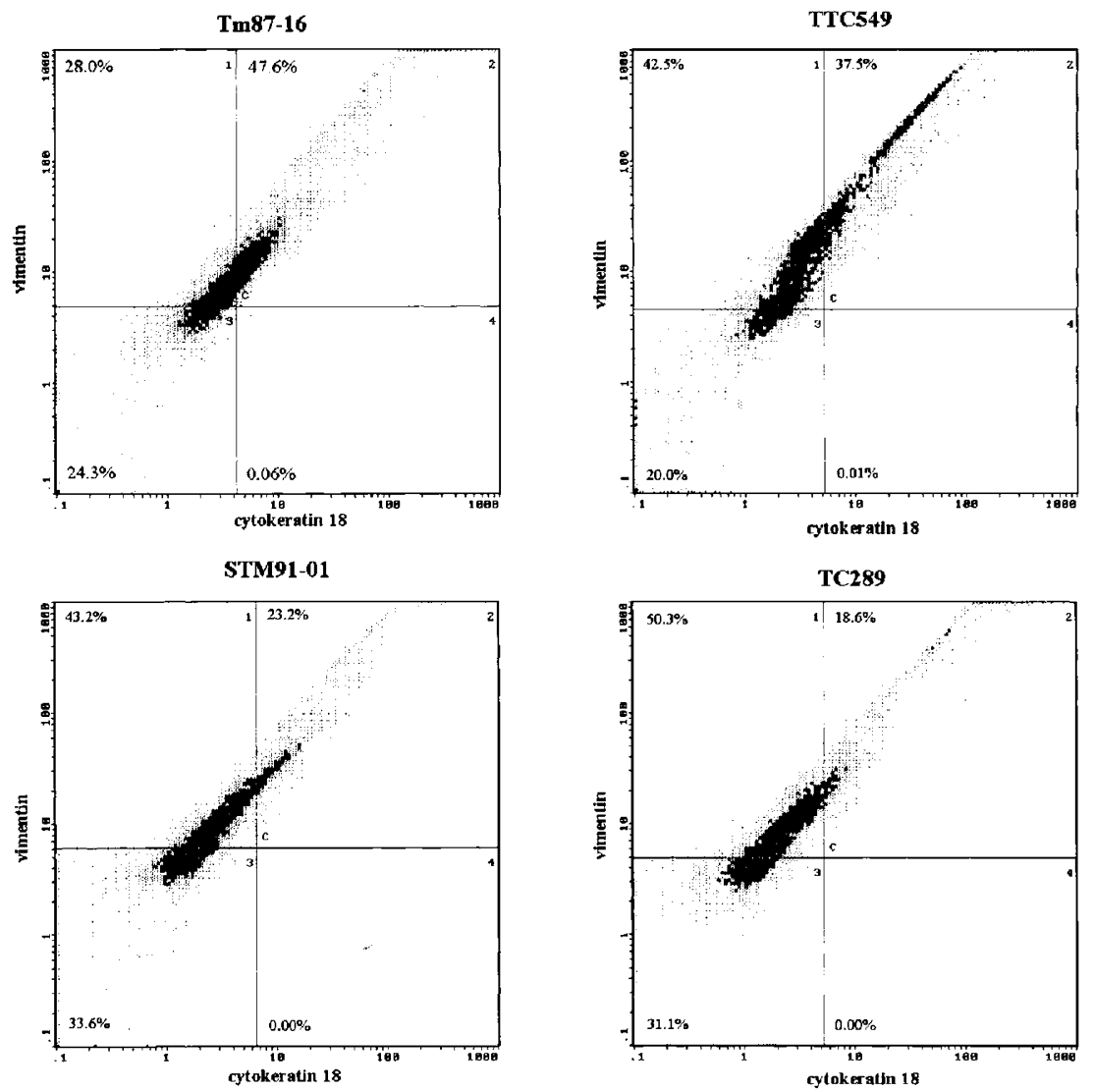

FIGURE 2. Flow cytometry analysis of cytokeratin 18 and vimentin expression in malignant rhabdoid tumor (MRT) cells. Vimentin was expressed by 66.4 to $80.0 \%$ of MRT cells, and cytokeratin 18 (CK 18) was expressed by 18.6 to $47.6 \%$ of MRT cells. The relative fluorescence intensity due to CK 18 (Oregon Green 488) and vimentin (Rhodamine Red-X) is plotted on the log scale $x$ - and $y$-axis, respectively.

(Fig. 4C). Vimentin was strongly expressed as an incomplete filamentous network at the cell periphery (Fig. 4B-C).

\section{STM91-01}

STM91-01 cells were mostly composed of round cells (Fig. 5A). These cells showed vague subcellular localization of vimentin and cytokeratins. Cytokeratins were expressed formed agglomerates (Fig. 5B) and were focally detected at the perinuclear region (data not shown). Some of the STM91-01 cells showed loop-like vimentin (Fig. 5C).

\section{TC289}

TC289 cells were composed of round cells and multinucleated giant cells with a few spindleshaped cells (Fig. 6A). These cells showed relatively distinct subcellular localization of vimentin and cytokeratins. In giant cells, cytokeratins were expressed as a few vague agglomerates, whereas vimentin formed a filament network. In round cells, the distribution patterns of vimentin and cytokeratins were the same as those seen for TTC549 and STM91-01. In spindle-shaped cells, vimentin was expressed mainly along the edge of the cytoplasm (Fig. 6B). Giant cells were used for three-dimen- sional-imaging analysis. Stereoscopic images revealed a close relation between vimentin and cytokeratins. An agglomerate of cytokeratins was enveloped by the vimentin filament network (Fig. 7).

\section{DISCUSSION}

MRT is a unique tumor that is characterized by rhabdoid appearance of cells with large hyalin-like globular inclusions at perinuclear regions of cytoplasm by hematoxylin-eosin stain. The inclusions are composed of whorls of intermediate filaments. Although several immunohistochemical studies with single-labeling methods have reported coexpression of cytokeratin and vimentin, no clear localization of these intermediate filaments in cytoplasm has been clarified $(9,10,13,17,18)$. With regard to cytokeratin subunits, Shiratsuchi et al. (18) reported that all six cases of MRT diffusely expressed CKs 8 and 18. Only one case of MRT also diffusely expressed CK 19. However, a few cases showed a focally limited positive immunoreactivity for CKs 7, 10, 13, and 17. Other cytokeratins including CK 3, 4, 5, 6, 10, 14, 16, and 20 were completely 

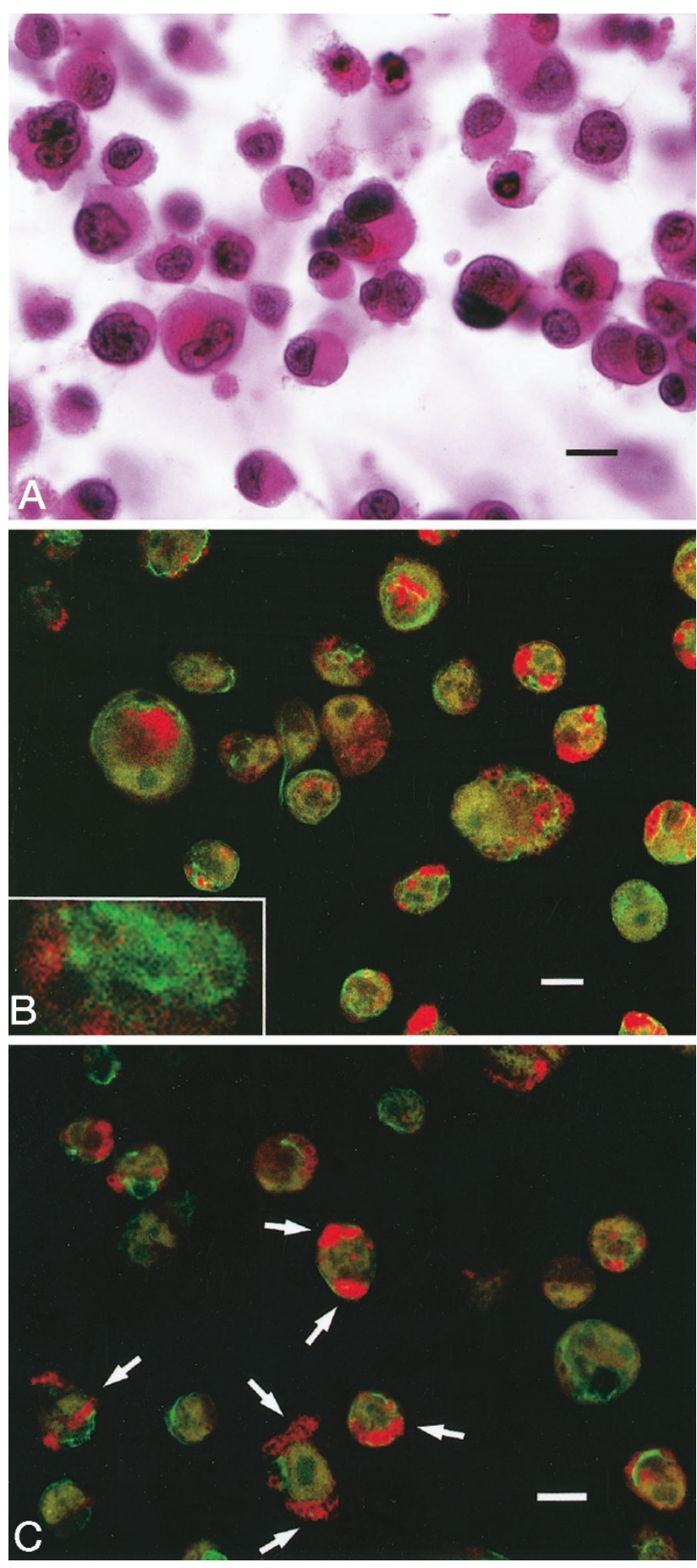

FIGURE 3. Case Tm87-16. A, hematoxylin and eosin stain (200×). B, dual imaging from a single section $(1024 \times 768$ pixels) of red (CK 8) and green (vimentin) fluorescence present in Tm87-16. Cytokeratin is expressed as clusters of globules. Zoomed vimentin is strongly expressed, forming an incomplete filamentous network. $\mathbf{C}$, in some cells, cytokeratin globules form lines, mainly at the cell periphery (1024 $\times 768$ pixels). Scale bars, $10 \mu \mathrm{M}$.

negative in MRT. In this study, double immunofluorescence and confocal laser scanning microscopy for morphological assessment of localization of CKs 8 and 18 and vimentin in MRT cells revealed clear localization of the two kinds of intermediate filaments and lack of a structural relationship between
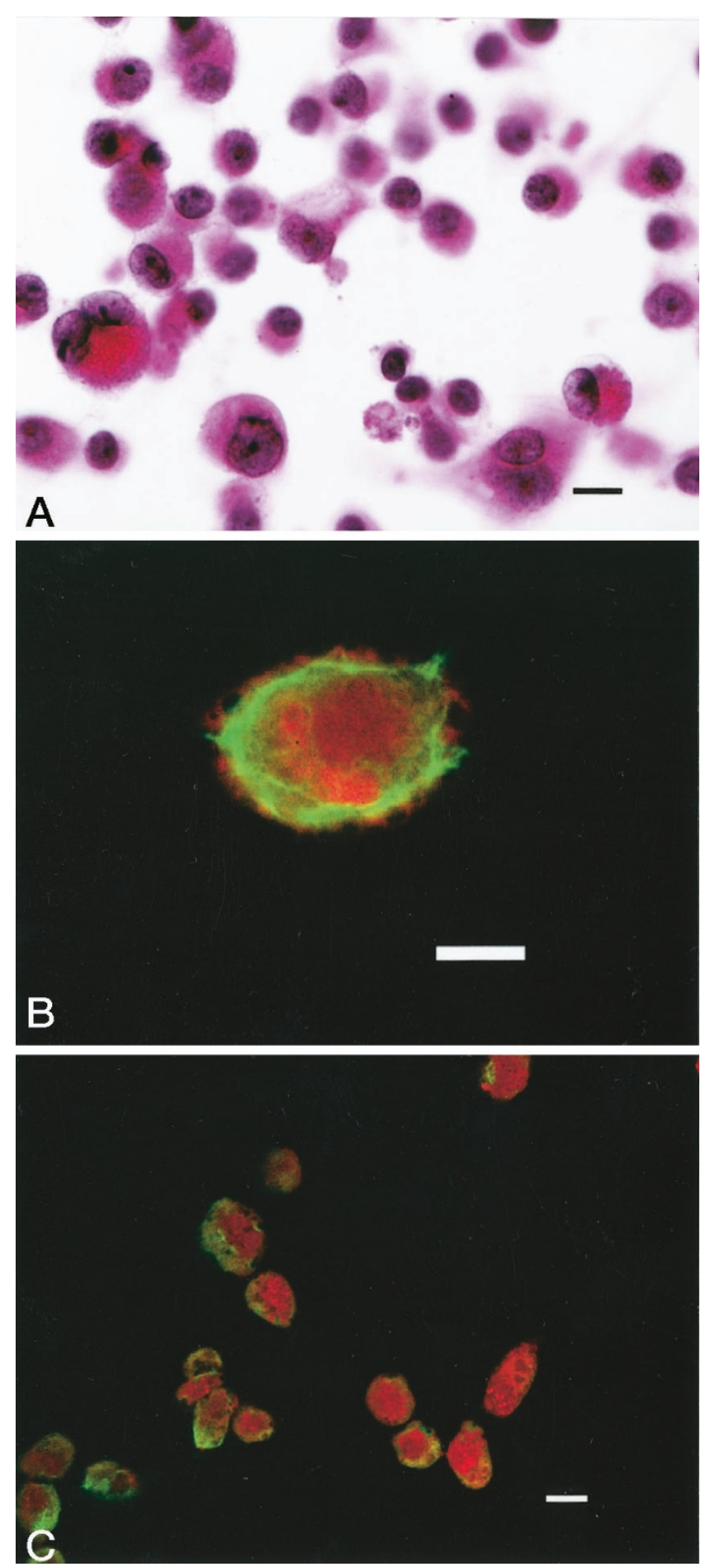

FIGURE 4. Case TTC549. A, hematoxylin and eosin stain $(200 \times)$. B, dual imaging from a single section $(496 \times 372$ pixels $)$ of cytokeratin (CK) 8 (red) and vimentin (green) fluorescence. Vimentin is strongly expressed, forming an incomplete filamentous network. $\mathbf{C}$, dual imaging from a single section $(1024 \times 768$ pixels) of CK 18 (red) and vimentin (green) fluorescence. Some cells expressed CK 18 as clusters of globules. Scale bars, $10 \mu \mathrm{M}$.

them within the cytoplasm. The flow cytometry analysis revealed the same patterns of coexpression of CK 18 and vimentin in all four MRT cell lines. Two proteins; cytokeratin and vimentin can be in the cytoplasm of the same cell of MRT, but in the absence of colocalization and lack of a structural relationship, there is no proof of a rela- 


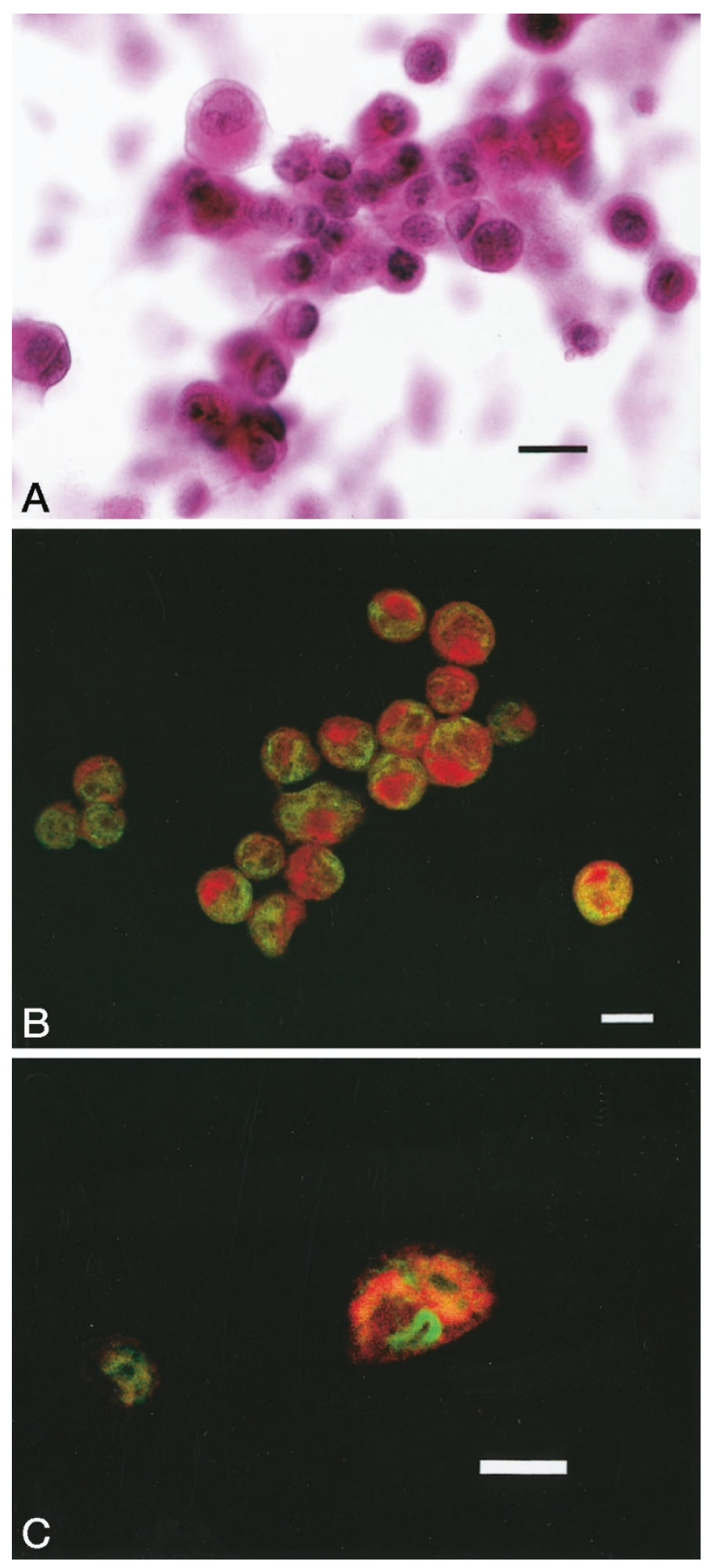

FIGURE 5. Case STM91-01. A, hematoxylin and eosin stain $(200 \times)$. B, dual imaging from a single section $(1024 \times 726$ pixels) of CK 18 (red) and vimentin (green). CK 18 is expressed in forming agglomerates. C, dual imaging from a single section $(504 \times 367$ pixels $)$ of CK 8 (red) and vimentin (green) fluorescence. Some cells show loop-like vimentin. Scale bars, $10 \mu \mathrm{m}$.

tionship to each other. An expression of vimentin in the overall cytoplasm of MRT cells, forming a complete or incomplete filamentous network, implied that vimentin played a role in forming cytoskeleton of MRT cells. Because globules and vague agglomerates of CKs 8 and 18 were scattered in the cytoplasm of MRT cells and were clearly distinguished

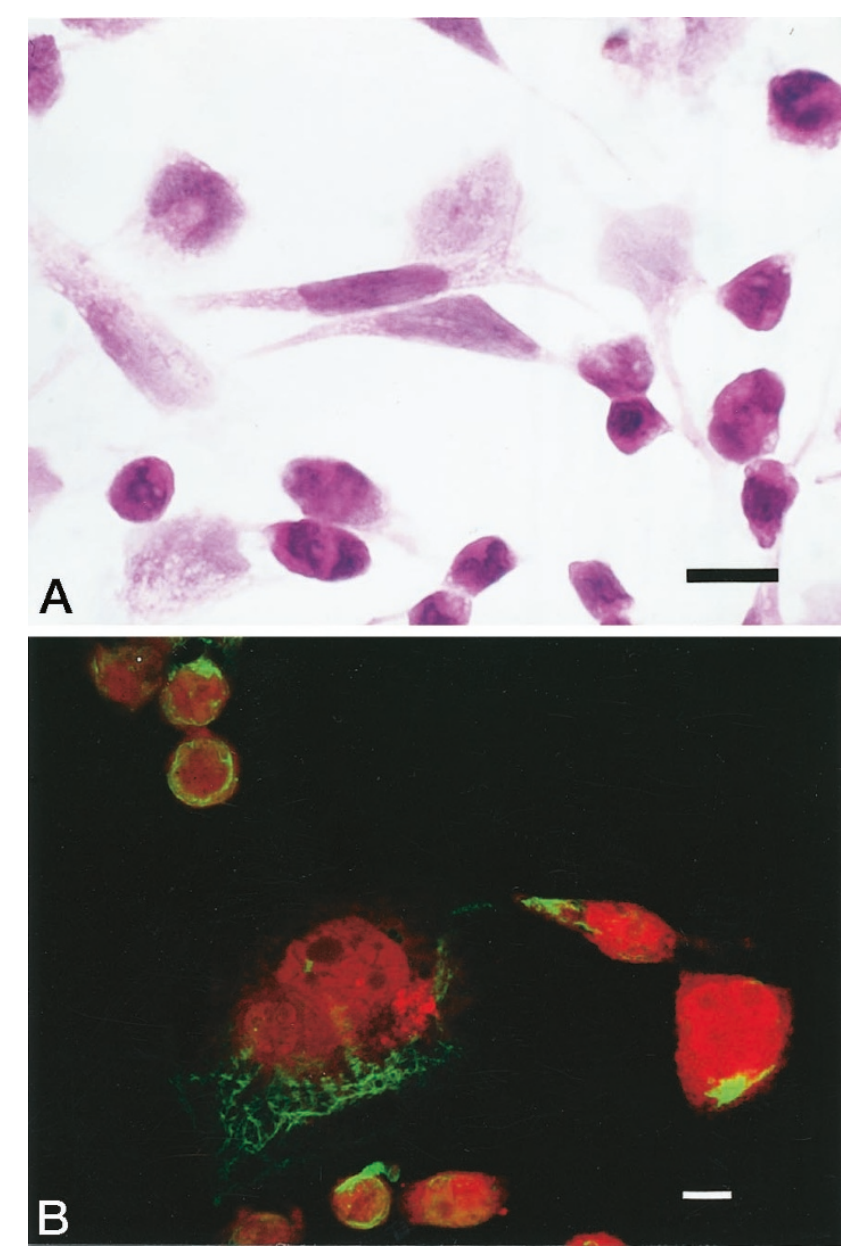

FIGURE 6. Case TC289. A, hematoxylin and eosin stain $(330 \times)$. B, dual volume project imaging from 20 sections $(1024 \times 768$ pixels $)$ of cytokeratin 18 (red) and vimentin (green) fluorescence. Giant cells show a few vague agglomerates of cytokeratins within a vimentin filament network. Round cells show diffuse cytokeratin and a cordlike or incomplete vimentin filament network. Spindle-shaped cells show diffuse cytokeratin and vimentin, mainly expressed at the cell periphery. Scale bars, $10 \mu \mathrm{M}$.

from vimentin filaments showing little significant colocalization, which was demonstrated by minimal to absent yellow (red/green overlays) signal, we believe that globules and vague agglomerates of CKs 8 and 18 are inclusions of MRT.

Cytokeratins are commonly expressed as particular pairs, which form heteropolymers in cells. For example, CK 8 is normally co-expressed with CK 18 to form a structural filament bundle. CKs 8 and 18 are mainly expressed in a variety of single-layered or simple epithelial tissues and are persistently expressed in a wide variety of carcinomas derived from the visceral epithelia, including the stomach, intestinal tract, liver, pancreas, and mammary gland (19). Also, expression of CKs 8 and 18 is observed in some malignant mesenchymal tumors such as leiomyosarcoma and malignant peripheral nerve sheath tumor (20), in addition to epithelioid sarcoma and synovial sarcoma $(20,21)$, which are classified as miscellaneous tumors. Therefore, the 


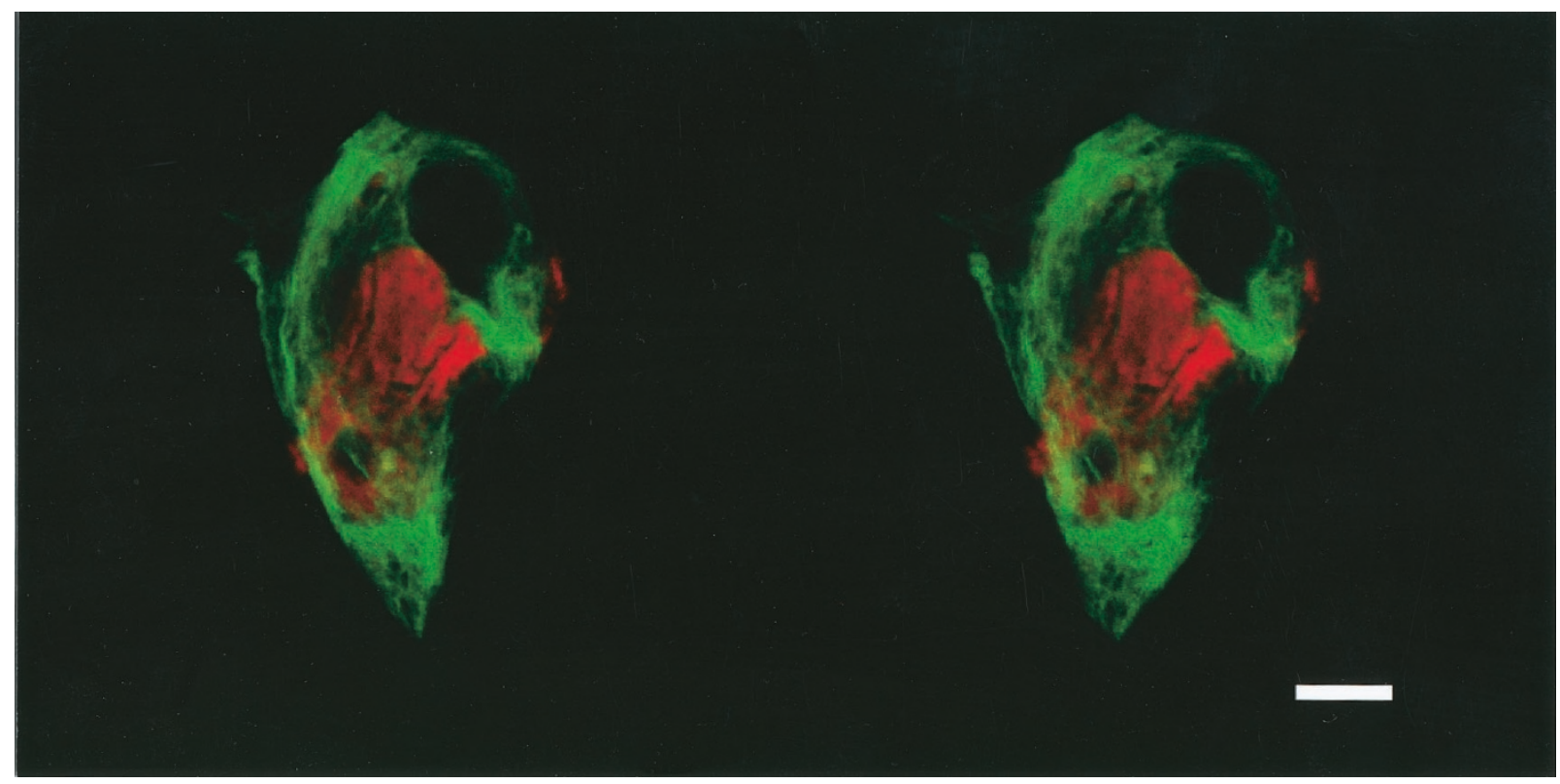

FIGURE 7. Stereoscopic imaging from 20 sections $(1024 \times 768$ pixels) of cytokeratin 8 (red) and vimentin (green) fluorescence present in Case TC289. Giant cells show that an agglomerate of cytokeratins is enveloped by a vimentin filament network. Scale bar, $10 \mu \mathrm{M}$.

expression of CKs 8 and 18 does not indicate any histological origin or tissue differentiation of MRT, for which histogenesis is still uncertain. Various cellular origins have been proposed for MRT, including neuroectodermal $(2,10,13,15)$, neural $(6$, 17), epithelial $(10,22)$, myogenic $(10,23)$, and smooth-muscle-cell (16) phenotype. Whatever its pathogenesis may be, the relatively uniform clinicopathological profile of MRT supports its acceptance as a specific disease entity of malignancy.

Several authors have reported a specific chromosomal abnormality comprising the deletion of $22 \mathrm{q}$, detected by established cell lines. Recently, the critical region of MRT has been mapped to chromosome segment 22q11.2, close to BCR $(14,24,25)$. The chromatin-remodeling $h S N F 5 / I N I 1$ gene at $22 \mathrm{q} 11.2$ has been reported in some MRT (26). The hSNF5/INI1 inactivation is mainly associated with homozygous deletions and mitotic recombinations (27). Mori et al. (28) have also isolated the Rab36 gene at 22q11.2. However, no morphological assessments of intermediate filaments about these genes have been reported yet.

It is supported that the globules and agglomerates of CKs 8 and 18 correspond with the characteristic ultrastructural finding, showing cytoplasmic whorls of intermediate filaments in MRT cells. It is known that several normal tissue cells and tumors co-express vimentin and another intermediate filament (cytokeratin, desmin, or glial filament protein) in the same or dissimilar pattern. In cultured vascular smooth muscle cells of human umbilical cord, CKs 8, 18, and 19 are co-expressed together with vimentin both in extended fibril forms and aggregated forms. Some cytokeratin fibrils coextended with vimentin fibrils. Some cytokeratin fibrils are clearly distinguished from adjacent vimentin fibrils (29). In cultured neonatal rat hepatocytes, both cytokeratin and vimentin are expressed as intermediate filament networks. Both intermediate filaments are highly interrelated and mostly colocalized. Vimentin filaments appear in the spread edges of the hepatocytes (30). Otherwise, in rhabdomyosarcoma and alveolar soft-part sarcoma, desmin and vimentin are colocalized within the same cells (31). In astrocytoma cells (U 333 CG/343 MG), glial filament protein and vimentin are mostly colocalized in the same fibrillar arrays (32). Interestingly, CKs 8 and 18 containing cytokeratin globules similar to inclusions of MRT are also seen in the Mallory bodies of alcoholic hepatitis (33), whereas MRT is dissimilar to this disease in vimentin expression. Mallory bodies are thought to be composed of normally assembled CKs 8 and 18, which are rendered by posttranslational alteration that occur after filament assembly (34). Such cytokeratin globules occur in several degenerative processes of many tissues. The globules and agglomerates of CKs 8 and 18 in MRT may be a secondary accumulation of intermediate filaments.

AcknowledgmentsWe are grateful to Dr. K. Hirano for electron microscopic analysis. The English used in this manuscript was revised by Miss K. Miller (Royal English Language Center, Fukuoka, Japan).

\section{REFERENCES}

1. Beckwith JB, Palmer NF. Histopathology and prognosis of Wilms tumor: results from the First National Wilms' Tumor Study. Cancer 1978;41:1937-48. 
2. Haas JE, Palmer NF, Weinberg AG, Beckwith JB. Ultrastructure of malignant rhabdoid tumor of the kidney: a distinctive renal tumor of children. Hum Pathol 1981;12:646-57.

3. Gonzalez-Crussi F, Goldschmidt RA, Hsueh W, Trujillo YP. Infantile sarcoma with intracytoplasmic filamentous inclusions: distinctive tumor of possible histiocytic origin. Cancer 1982;49:2365-75.

4. Tsuneyoshi M, Daimaru Y, Hashimoto H, Enjoji M. Malignant soft tissue neoplasms with the histologic features of renal rhabdoid tumors: an ultrastructural and immunohistochemical study. Hum Pathol 1985;16:1235-42.

5. Kodet R, Newton WA Jr, Sachs N, Hamoudi AB, Raney RB, Asmar L, et al. Rhabdoid tumors of soft tissues: a clinicopathologic study of 26 cases enrolled on the Intergroup Rhabdomyosarcoma Study. Hum Pathol 1991;22:674-84.

6. Bonnin JM, Rubinstein LJ, Palmer NF, Beckwith JB. The association of embryonal tumors originating in the kidney and in the brain: a report of seven cases. Cancer 1984;54: 2137-46.

7. Biggs PJ, Garen PD, Powers JM, Garvin AJ. Malignant rhabdoid tumor of the central nervous system. Hum Pathol 1987; 18:332-7.

8. Parham DM, Weeks DA, Beckwith JB. The clinicopathologic spectrum of putative extrarenal rhabdoid tumors. An analysis of 42 cases studied with immunohistochemistry or electron microscopy. Am J Surg Pathol 1994;18:1010-29.

9. Vogel AM, Gown AM, Caughlan J, Haas JE, Beckwith JB. Rhabdoid tumors of the kidney contain mesenchymal specific and epithelial specific intermediate filament proteins. Lab Invest 1984;50:232-8.

10. Tsokos M, Kouraklis G, Chandra RS, Bhagavan BS, Triche TJ. Malignant rhabdoid tumor of the kidney and soft tissues. Evidence for a diverse morphological and immunocytochemical phenotype. Arch Pathol Lab Med 1989;113:115-20.

11. Weeks DA, Beckwith JB, Mierau GW, Luckey DW. Rhabdoid tumor of kidney. A report of 111 cases from the National Wilms' Tumor Study Pathology Center. Am J Surg Pathol 1989;13:439-58.

12. Karnes PS, Tran TN, Mei YC, Bogenmann E, Shimada H, Kuang LY. Establishment of a rhabdoid tumor cell line with a specific chromosomal abnormality, $46, \mathrm{XY}, \mathrm{t}(11 ; 12)(\mathrm{p} 15.5$; q11.23). Cancer Genet Cytogenet 1991;56:31-8.

13. Ota S, Crabbe DCG, Tran TN, Triche TJ, Shimada H. Malignant rhabdoid tumor. A study with two established cell lines. Cancer 1993;71:2862-72.

14. Biegel JA, Allen CS, Kawasaki K, Shimizu N, Budarf ML, Bell CJ. Narrowing the critical region for a rhabdoid tumor locus in 22q11. Genes Chromosom Cancer 1996;16:94-105.

15. Suzuki A, Ohta S, Shimada M. Gene expression of malignant rhabdoid tumor cell lines by reverse transcriptasepolymerase chain reaction. Diagn Mol Pathol 1997;6:326-32.

16. Kinoshita Y, Tamiya S, Oda Y, Mimori K, Inoue H, Ohta S, et al. Establishment and characterization of malignant rhabdoid tumor of the kidney. Oncol Rep 2001;8:43-8.

17. Sugimoto $T$, Hosoi $H$, Horii $Y$, Ishida $H$, Mine $H$, Takahashi $\mathrm{K}$, et al. Malignant rhabdoid-tumor cell line showing neural and smooth-muscle-cell phenotypes. Int J Cancer 1999;82: 678-86.

18. Shiratsuchi T, Oshiro Y, Saito T, Itakura E, Kinoshita Y, Tamiya S, et al. Cytokeratin subunits of inclusion bodies in rhabdoid cells: immunohistochemical and clinicopathological study of malignant rhabdoid tumor and epithelioid sarcoma. Int J Surg Pathol 2001;9:37-48.

19. Moll R, Franke WW, Schiller DL, Geiger B, Krepler R. The catalog of human cytokeratins: patterns of expression in normal epithelia, tumors and cultured cells. Cell 1982;31:1124.

20. Miettinen M. Keratin subsets in spindle cell sarcomas. Keratins are widespread but synovial sarcoma contains a distinctive keratin polypeptide pattern and desmoplakins. Am J Pathol 1991;138:505-13.

21. Leader M, Patel J, Makin C, Henry K. An analysis of the sensitivity and specificity of the cytokeratin marker CAM 5.2 for epithelial tumours. Results of a study of 203 sarcomas, 50 carcinomas and 28 malignant melanomas. Histopathology 1986;10:1315-24.

22. Parham DM, Peiper SC, Robicheaux G, Ribeiro RC, Douglass EC. Malignant rhabdoid tumo of the liver: evidence for epithelial differentiation. Arch Pathol Lab Med 1988;112:61-4.

23. Giangaspero F, Zanetti G, Mancini A. Sarcomatous variant of Wilms' tumor: a light and immunohistochemical study of four cases. Tumori 1981;63:367-73.

24. Schofield DE, Beckwith JB, Sklar J. Loss of heterozygosity at chromosome regions 22q11-12 and 11p15.5 in renal rhabdoid tumors. Genes Chromosom Cancer 1996;15:10-7.

25. Rosty C, Peter M, Zucman J, Validire P, Delattre O, Aurias A. Cytogenetic and molecular analysis of a $\mathrm{t}(1 ; 22)(\mathrm{p} 36 ; \mathrm{q} 11.2)$ in a rhabdoid tumor with a putative homozygous deletion of chromosome 22. Genes Chromosom Cancer 1998;21:82-9.

26. Versteege I, Sévenet N, Lange J, Rousseau-Merck MF, Ambros $\mathrm{P}$, Handgretinger $\mathrm{R}$, et al. Truncating mutations of hSNF5/INI1 in aggressive paediatric cancer. Nature 1998; 394:203-6.

27. Rousseau-Merck MF, Versteege I, Legrand I, Couturier J, Mairal A, Delattre O, et al. hSNF5/INI1 inactivation is mainly associated with homozygous deletions and mitotic recombinations in rhabdoid tumors. Cancer Res 1999;59:3152-6.

28. Mori T, Fukuda Y, Kuroda H, Matsumura T, Ota S, Sugimoto $\mathrm{T}$, et al. Cloning and characterization of a novel Rab-family gene, Rab36, within the region at 22q11.2 that is homozygously deleted in malignant rhabdoid tumors. Biochem Biophys Res Commun 1999;254:594-600.

29. Bader BL, Jahn L, Franke WW. Low level expression of cytokeratin 8, 18 and 19 in vascular smooth muscle cells of human umbilical cord and in cultured cells derived therefrom, with an analysis of the chromosomal locus containing the cytokeratin 19 gene. Eur J Cell Biol 1988;47:300-19.

30. Pagan R, Martín I, Alonso A, Llobera M, Vilaró S. Vimentin filaments follow the preexisting cytokeratin network during epithelial-mesenchymal transition of cultured neonatal rat hepatocytes. Exp Cell Res 1996;222:333-44.

31. Denk H, Krepler R, Artlieb U, Gabbiani G, Rungger-Brändle $\mathrm{E}$, Leoncini $\mathrm{P}$, et al. Proteins of intermediate filaments. An immunohistochemical and biochemical approach to the classification of soft tissue tumors. Am J Pathol 1983;110: 193-208.

32. Quinlan RA, Franke WW. Molecular interactions in intermediate-sized filaments revealed by chemical crosslinking. Heteropolymers of vimentin and glial filament protein in cultured human glioma cells. Eur J Biochem 1983; 132:477-84.

33. Hazan R, Denk H, Franke WW, Lackinger E, Schiller DL. Change of cytokeratin organization during development of Mallory bodies as revealed by a monoclonal antibody. Lab Invest 1986;54:543-53.

34. Pollanen MS, Markiewicz P, Weyer L, Goh MC, Bergeron C. Mallory body filaments become insoluble after normal assembly into intermediate filaments. Am J Pathol 1994;145: $1140-7$. 